\title{
Low expression of the GOPC is a poor prognostic marker in colorectal cancer
}

\author{
NOBUYOSHI OHARA ${ }^{1}$, NAOTSUGU HARAGUCHI ${ }^{1}$, JUN KOSEKI ${ }^{2}$, YUJIRO NISHIZAWA $^{1}$, KENJI KAWAI ${ }^{1}$, \\ HIDEKAZU TAKAHASHI ${ }^{1}$, JUNICHI NISHIMURA ${ }^{1}$, TAISHI HATA ${ }^{1}$, TSUNEKAZU MIZUSHIMA ${ }^{1}$, \\ HIROFUMI YAMAMOTO ${ }^{1}$, HIDESHI ISHII ${ }^{2}$, YUICHIRO DOKI ${ }^{1}$ and MASAKI MORI ${ }^{1}$ \\ Departments of ${ }^{1}$ Gastroenterological Surgery and ${ }^{2}$ Cancer Profiling Discovery, \\ Graduate School of Medicine, Osaka University, Osaka 565-0871, Japan
}

Received December 30, 2015; Accepted February 23, 2017

DOI: $10.3892 / \mathrm{ol} .2017 .6817$

\begin{abstract}
The Golgi-associated PDZ- and coiled-coil motif-containing (GOPC) protein controls the intracellular trafficking of numerous integral membrane proteins. Knockdown of GOPC increases activation of the mitogen-activated protein kinase-extracellular signal-regulated kinase $1 / 2$ pathway and cancer cell progression in colorectal cancer. The present study aimed to clarify the correlation between GOPC expression and prognosis in colorectal cancer. Total RNA was extracted from 153 clinical colorectal cancer specimens and GOPC expression was evaluated using reverse transcription-quantitative polymerase chain reaction. The correlation between GOPC expression and clinicopathological factors was analyzed, along with the association of GOPC expression with overall survival (OS) and with recurrence-free survival (RFS). Lower expression of GOPC was significantly associated with a high frequency of venous invasion $(\mathrm{P}=0.001)$ and to poorer OS and RFS based on Kaplan-Meier analysis. In addition, multivariate analyses using a Cox proportional hazards model identified lower expression of GOPC to be an independent prognostic factor for colorectal cancer (hazard ratio $=2.800 ; 95 \%$ confidence interval; 1.121-7.648; $\mathrm{P}=0.027)$. Lower expression of GOPC revealed a high frequency of venous invasion and associated with poorer prognosis for patients with colorectal cancer.
\end{abstract}

Correspondence to: Dr Naotsugu Haraguchi, Department of Gastroenterological Surgery, Graduate School of Medicine, Osaka University, 2-2, Yamadaoka, Suita-shi, Osaka 565-0871, Japan

E-mail: nharaguchi@gesurg.med.osaka-u.ac.jp

Key words: golgi-associated PDZ- and coiled-coil motif-containing, PDZ domain protein interacting specifically with TC10, Fused in Glioblastoma, reverse transcription-quantitative polymerase chain reaction, colorectal cancer, prognostic marker

\section{Introduction}

The mortality rate from colorectal cancer is the third highest in men (being behind that of lung and prostate cancer) and second in women (being behind breast cancer) in the United States (1). Even when patients undergo curative surgery for advanced cancer, recurrence can still occur. Markers that relate closely to cancer progression and metastasis would enable early diagnosis and intervention. Thus, the identification of novel markers that predict cancer progression is important for planning clinical strategies. In addition, the identification of such markers could lead to the development of novel therapeutic agents. In colorectal cancer, various molecular-targeted drugs have been developed and clinically applied in previous years (2-8). In addition, the assessment of specific genes including cancer progression gene sets via development of chip technology has led to tailor-made therapy.

The present study focused on the Golgi-associated PDZ-and coiled-coil motif-containing (GOPC) since it has been reported that the knockdown of GOPC in cells increases activation of the mitogen-activated protein kinase (MAPK)-extracellular signal-regulated kinase (Erk) 1/2 pathway. The MAPK-Erk1/2 pathway is a chief cellular signal transduction pathway that regulates cell differentiation, proliferation, survival and migration in colorectal cancer (9-13). The present study aimed to elucidate the correlation between GOPC expression and clinicopathological factors and prognosis in colorectal cancer.

\section{Materials and methods}

Patients and samples. GOPC expression was assessed for each of nine clinical samples of colorectal cancer and normal mucosa using reverse transcription-quantitative PCR (RT-qPCR). An additional 153 clinical colorectal cancer samples were used to assess the correlation of GOPC expression and clinicopathological factors or prognosis. For immunohistochemical analysis, 10 normal colorectal mucosa and 10 colorectal cancer tissue specimens were used. All samples were obtained by surgery between March 2003 and June 2006 at Osaka University, Minoh City Hospital, Kansai Rosai Hospital, Kinki Central Hospital of the Mutual Aid Association of Public School Teachers, National Hospital Organization Osaka 
National Hospital, NTT (Nippon Telegraph And Telephone) West Osaka Hospital, Osaka Medical Center for Cancer and Cardiovascular Diseases, Saiseikai Suita Hospital, Sakai City Medical Center and Toyonaka Municipal Hospital (all in Osaka, Japan). Every patient provided informed consent and the present study was approved by the Research Ethics Board of each institution.

Assessment of tumor stage. Tumor stages were defined according to the tumor node metastasis (TNM) staging system (14).

Assessment of clinicopathological and prognostic factors. The present study assessed the correlation between GOPC expression and clinical characteristics, venous invasion, lymph invasion, tumor invasion, lymph node metastasis, TNM stage, overall survival (OS) and recurrence-free survival (RFS). The 153 colorectal cancer samples included 32 TNM stage 0/I cases, 45 stage II cases, 58 stage III cases and 18 stage IV cases according to the UICC classification for colorectal cancer.

Processing $m R N A$ and $R T-q P C R$. Total RNA was extracted from frozen tumor tissue using miRNeasy Mini kit (Qiagen AB, Sollentuna, Sweden). No DNase treatment was performed. Total RNA was then reverse transcribed to cDNA using the High Capacity RNA-to-cDNA ${ }^{\mathrm{TM}}$ kit (Applied Biosystems; Thermo Fisher Scientific, Inc., Waltham, MA, USA), according to the manufacturer's protocol. cDNA was the amplified by RT-qPCR using the Light Cycler $^{\circledR} 2.0$ DX400 (Roche Diagnostics, Basel, Switzerland). The PCR reaction mixture consisted of $0.5 \mu \mathrm{l}$ of cDNA, $5.0 \mu \mathrm{l}$ of THUNDERBIRD ${ }^{\mathrm{TM}}$ $\mathrm{SYBR}^{\circledR}$ qPCR Mix (Toyobo Co., Ltd., Osaka, Japan), $4.0 \mu \mathrm{l}$ of water and $0.5 \mu \mathrm{l}$ of each primer. The GOPC primers were: Forward, 5'-GTGGATGTGGATCTGCTCCT-3' and reverse, 5'-CCTCCAGCTTGTGGTTGATT-3'. Primers for GAPDH, the internal control, were: Forward, 5'-CAACTACATGGT TTACATGTTC-3' and reverse, 5'-GCCAGTGGACTCCAC GAC-3'. The normalization was performed by standard curve method (15). The amplification protocol consisted of 55 cycles of: Denaturation at $95^{\circ} \mathrm{C}$ for $5 \mathrm{sec}$, annealing at $60^{\circ} \mathrm{C}$ for $5 \mathrm{sec}$ and extension at $72^{\circ} \mathrm{C}$ for $30 \mathrm{sec}$. The RT-qPCR experiment was performed 7 times.

Immunohistochemical staining. The expression of the GOPC protein was assessed by immunohistochemical staining of formalin-fixed and paraffin-embedded normal colorectal mucosa and colorectal cancer tissue sections. The surgical tissue samples were placed overnight at room temperature in $10 \%$ formalin before paraffin embedding. Briefly, $3.5 \mu \mathrm{m}$ thick sections were incubated overnight at $4^{\circ} \mathrm{C}$ using the rabbit polyclonal anti-GOPC antibody (dilution, 1:1,000; \#ab37036; Abcam, Cambridge, UK) subsequent to immersion and blockade of endogenous peroxidase activity. The blocking was for $20 \mathrm{~min}$ at room temperature using VECTASTAIN Elite ABC horseradish peroxidase kit (Rabbit IgG; \#PK-6101; Vector Laboratories, Burlingame, CA, USA). Hematoxylin was used for nuclear staining for $1 \mathrm{~min}$. Dehydration was performed using 60, 70, 80, 90 and 95\% ethanol for $1 \mathrm{~min}$ each, 100\% ethanol for $2 \mathrm{~min}$ twice and xylene for $5 \mathrm{~min}, 3$ times. The specimens were visualized on the light field using a confocal microscope BZ-X710 (Keyence Corporation, Osaka, Japan) and BZ-X analyzer (v. 1.3.0.3; Keyence Corporation).

Statistical analyses. Statistical analyses were performed using Fisher's exact tests to compare the differences between the two groups. The cumulative probabilities of OS or RFS were compared between these two groups by the Kaplan-Meier method with the log-rank test to calculate significant differences. Cases of non-curative resection were excluded from the RFS analyses. Univariate and multivariate analyses for OS and RFS were performed to evaluate independent prognostic factors using a Cox proportional hazards model. All statistical analyses were performed with JMP Pro software (version 11; JMP, Buckinghamshire, UK). $\mathrm{P}<0.05$ was considered to indicate a statistically significant difference.

\section{Results}

Correlation between GOPC mRNA expression and clinicopathological factors. Firstly, RT-qPCR was used to assess the expression of GOPC in normal colorectal mucosa and colorectal cancer tissue in nine clinical samples. The Wilcoxon rank-sum test was used to assess the statistical significance. GOPC expression in normal colorectal mucosa specimens was significantly increased compared with colorectal cancer specimens ( $\mathrm{P}=0.002$; Fig. $1 \mathrm{~A})$. The GOPC expression in the additional 153 colorectal cancer specimens was then assessed. Data obtained from RT-qPCR was investigated to see if it fit Gaussian distribution with the Shapiro-Wilk test, and it did not. Thus, the median value was used to classify the higher (GOPC high) and lower (GOPC low) expression groups and clinicopathological characteristics were assessed based on the level of GOPC expression. Based on the median score to separate the GOPC high and low groups (Fig. 1B), there were 77 GOPC high cases, and 76 GOPC low cases. The baseline characteristics are presented in Table I. The GOPC high group included 48 men and 29 women whereas the GOPC low group included 47 men and 29 women. The groups did not differ in the site of primary disease or size of the primary tumor, and CEA and CA19-9 levels also did not differ. In the analysis of clinicopathological factors, the proportion of positive venous invasion was significantly increased in the GOPC low group compared with the GOPC high group $(\mathrm{P}=0.001)$. Histological type, lymphatic invasion, depth of tumor invasion, lymphatic nodule metastasis, and TNM stages were not observed to differ between the two groups (Table II).

Correlation between GOPC mRNA expression and clinical outcome. The correlation between GOPC expression and clinical outcome was assessed by comparison of the GOPC high and low groups. OS and RFS were assessed by the Kaplan-Meier method using the log-rank test. The Kaplan-Meier curves demonstrated that there was a significantly poorer OS in the GOPC low group compared with the GOPC high group $(\mathrm{P}=0.015$; Fig. 2A). Univariate and multivariate analyses identified lymphatic invasion to be an independent prognostic factor for OS [hazard ratio $(\mathrm{HR})=7.628 ; 95 \%$ confidence interval (CI), 1.441-141.2; $\mathrm{P}=0.012$; Table III].

The correlation of GOPC expression and RFS was assessed in 131 patients ( 22 of the 153 patients had undergone 
Table I. Baseline characteristics of the GOPC high and low groups.

\begin{tabular}{lccc}
\hline & \multicolumn{2}{c}{ GOPC expression } & \\
\cline { 2 - 3 } $\begin{array}{l}\text { Clinical } \\
\text { characteristics }\end{array}$ & $\begin{array}{c}\text { High group } \\
(\mathrm{n}=77)\end{array}$ & $\begin{array}{c}\text { Low group } \\
(\mathrm{n}=76)\end{array}$ & P-value \\
\hline Gender & & & NS \\
Male & 48 & 47 & \\
Female & 29 & 29 & 0.191 \\
Primary site & & 48 & \\
Colon & 40 & 28 & 0.552 \\
Rectum & & & \\
Tumor size, cm & $6(2-9.5)$ & $4.7(1.3-15.5)$ & \\
Median (range) & & & \\
CEA, ng/ml & $4(1-204)$ & $4.8(0.9-7,636)$ & \\
Median (range) & 0.432 & & \\
& & & \\
CA19-9, U/ml & & & \\
Median (range) & $13(2-10,740)$ & $15(0-186,061)$ & \\
\hline
\end{tabular}

GOPC, Golgi-associated PDZ- and coiled-coil motif-containing; CEA, carcinoembryonic antigen; CA, cancer antigen; NS, not significant.

non-curative surgery and were excluded from RFS analysis). Adjuvant chemotherapy was used in 27 GOPC high and 24 GOPC low cases. The 4 regimens of adjuvant chemotherapy were: Uracil-tegafur with leucovorin; Uracil-tegafur with doxifluridine; Uracil-tegafur with irinotecan; 5-fluorouracil with l-leucovorin. Relapse was observed in 25 patients: 8 in the GOPC high group and 17 in the GOPC low group. The proportion of recurrence was significantly higher in the GOPC low group ( $\mathrm{P}=0.049$; Table IV). The Kaplan-Meier curves indicated that RFS was significantly reduced in the GOPC low group compared with the GOPC high group $(\mathrm{P}=0.020$; Fig. 2B). Univariate and multivariate analyses identified lymph node metastasis $(\mathrm{HR}=2.861 ; 95 \% \mathrm{CI}, 1.138-7.880$; $\mathrm{P}=0.024)$ and lower GOPC expression $(\mathrm{HR}=2.800 ; 95 \% \mathrm{CI}$, 1.121-7.648; $\mathrm{P}=0.027)$ to be independent prognostic factors for RFS (Table V).

In analyses according to each stage, OS in the GOPC low group was poorer compared with in the GOPC high group at stage III ( $\mathrm{P}=0.044)$ and stage IV $(\mathrm{P}=0.054$; Fig. 3$)$.

Expression of GOPC protein in normal colorectal mucosa and colorectal cancer tissue. Immunohistochemical analysis was performed to assess the protein expression of GOPC in 10 sections each of normal colorectal mucosa and colorectal cancer tissue. Representative staining of GOPC in the normal colorectal mucosa and colorectal cancer tissue was observed (Fig. 4). GOPC protein expression in normal mucosa was increased compared with in cancer tissue and expression localized in the cytoplasm or cell surface membrane (Fig. 4A and $\mathrm{B}$ ). As for the GOPC expression in cancer tissue, a high expression was observed at the surface of cancerous tissue,
Table II. Correlation between GOPC expression and pathological characteristics.

\begin{tabular}{|c|c|c|c|}
\hline \multirow[b]{2}{*}{$\begin{array}{l}\text { Pathological } \\
\text { characteristics }\end{array}$} & \multicolumn{2}{|c|}{ GOPC expression } & \multirow[b]{2}{*}{ P-value } \\
\hline & $\begin{array}{l}\text { High group } \\
\quad(n=77)\end{array}$ & $\begin{array}{l}\text { Low group } \\
\quad(n=76)\end{array}$ & \\
\hline \multicolumn{4}{|c|}{ Histological type } \\
\hline tub1, tub2 & 75 & 69 & 0.097 \\
\hline por, sig & 2 & 7 & \\
\hline \multicolumn{4}{|l|}{ Lymph invasion } \\
\hline Negative & 32 & 25 & 0.316 \\
\hline Positive & 45 & 51 & \\
\hline \multicolumn{4}{|l|}{ Venous invasion } \\
\hline Negative & 50 & 29 & $0.001^{\mathrm{a}}$ \\
\hline Positive & 27 & 47 & \\
\hline \multicolumn{4}{|l|}{ Tumor invasion } \\
\hline T0-2 & 18 & 18 & NS \\
\hline T3-4 & 59 & 58 & \\
\hline \multicolumn{4}{|l|}{$\begin{array}{l}\text { Lymph node } \\
\text { metastasis }\end{array}$} \\
\hline Negative & 41 & 39 & 0.871 \\
\hline Positive & 36 & 37 & \\
\hline \multicolumn{4}{|l|}{ TNM stage } \\
\hline 0-II & 40 & 37 & 0.747 \\
\hline III-IV & 37 & 39 & \\
\hline \multicolumn{4}{|l|}{ Metastasis site } \\
\hline Liver & 5 & 9 & \\
\hline Pleura & 1 & 3 & \\
\hline Other & 1 & 1 & \\
\hline \multicolumn{4}{|l|}{ Curability } \\
\hline Curative & 67 & 64 & 0.651 \\
\hline Non-curative & 10 & 12 & \\
\hline
\end{tabular}

${ }^{\mathrm{a}} \mathrm{P}<0.05$. GOPC, Golgi-associated PDZ- and coiled-coil motifcontaining; TNM, tumor node metastasis; NS, not significant.

whilst low expression was observed at the invasive front (Fig. 4C and D).

\section{Discussion}

GOPC, also known as PDZ domain protein interacting specifically with TC10 or Fused in Glioblastoma (FIG), and cystic fibrosis transmembrane conductance regulator-associated ligand, controls the trafficking of numerous integral membrane proteins from the trans-Golgi network to the cell surface (16-19). Its domain structure consists of an N-terminal region with two coiled-coil domains and a $\mathrm{C}$-terminal PDZ domain (16). The PDZ domain mediates interactions with frizzled, a Wnt receptor (16), and TC10, a member of the Rho-family GTPases (17). In addition, GOPC regulates various proteins including the soluble $\mathrm{N}$-ethylmaleimide sensitive fusion protein attachment protein receptor (Q-SNARE) protein 

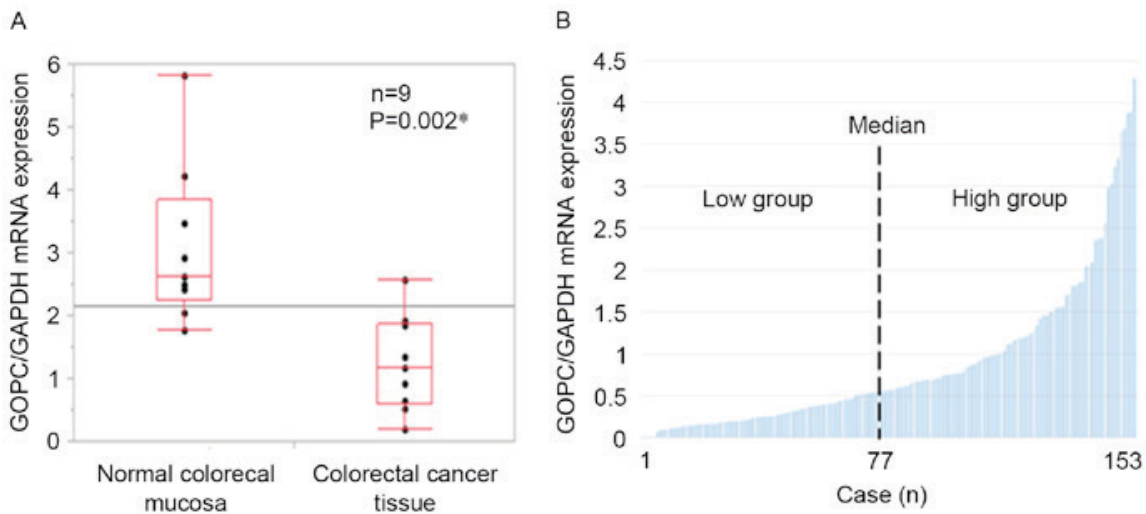

Figure 1. Results for GOPC mRNA expression by RT-qPCR. (A) Association between normal colorectal mucosa and colorectal cancer tissue by box plot chart. Statistical analyses were performed using the Wilcoxon rank-sum test. $\mathrm{P}<0.05$ was regarded as statistically significant. (B) Relative GOPC mRNA expression in 153 primary cancer tissue samples. The samples were divided into two groups split at the median value of GOPC expression. GOPC, Golgi-associated PDZ- and coiled-coil motif-containing; RT-qPCR, reverse transcription-quantitative polymerase chain reaction; GAPDH, glyceraldehyde 3-phosphate dehydrogenase.
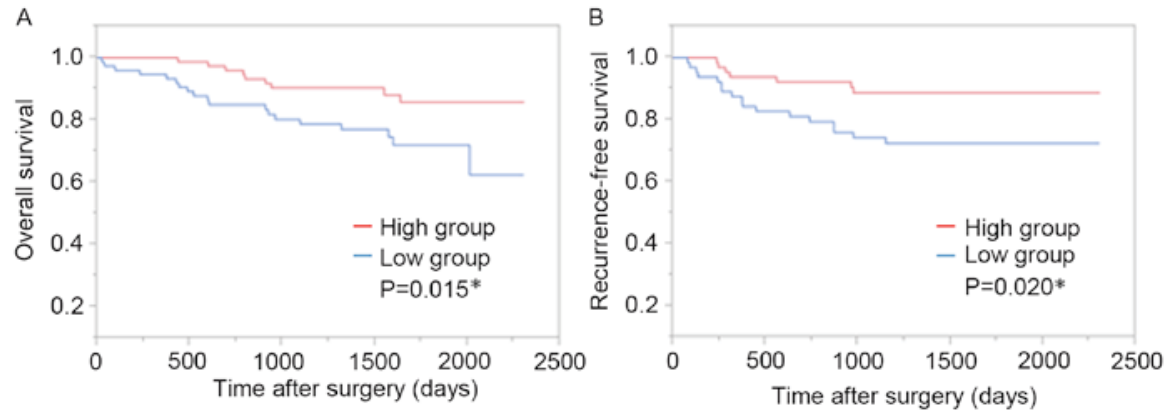

Figure 2. Kaplan-Meier curves for OS or RFS according to GOPC expression. (A) Cumulative OS for all cases. (B) Cumulative RFS for cases of curative resection. High and low groups were separated by the median score of GOPS expression. OS or RFS in the GOPC low group was significantly poorer compared with the GOPC high group. OS, overall survival; RFS, recurrence-free survival; GOPC, Golgi-associated PDZ- and coiled-coil motif-containing.
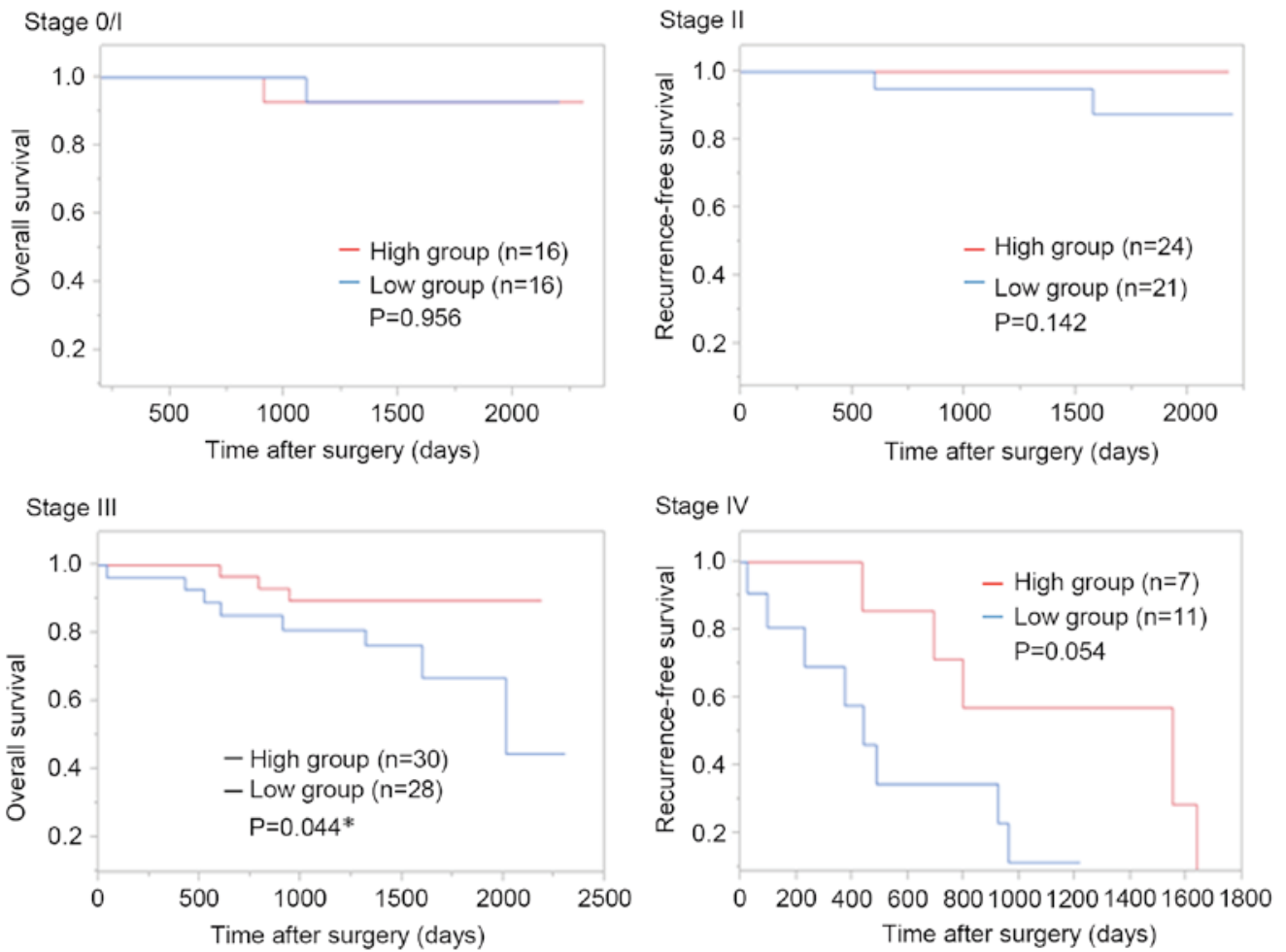

Figure 3. Kaplan-Meier curves for OS according to each stage. High and low groups were separated by the median score of GOPS expression. OS in the GOPC low group was poorer compared with the GOPC high group; stage III $(\mathrm{P}=0.044)$ and stage IV $(\mathrm{P}=0.054)$. OS, overall survival; GOPC, Golgi-associated PDZ- and coiled-coil motif-containing. 
Table III Results of univariate and multivariate analyses for overall survival in a Cox proportional hazards model.

\begin{tabular}{|c|c|c|c|c|c|c|c|}
\hline \multirow[b]{2}{*}{ Characteristics } & \multirow[b]{2}{*}{$\mathrm{n}$} & \multicolumn{3}{|c|}{ Univariate analysis } & \multicolumn{3}{|c|}{ Multivariate analysis } \\
\hline & & HR & $95 \% \mathrm{CI}$ & $P$ value & HR & $95 \%$ CI & P-value \\
\hline \multicolumn{8}{|l|}{ Gender } \\
\hline Male/Female & $95 / 58$ & 0.821 & $0.398-1.779$ & 0.621 & & & \\
\hline $\begin{array}{l}\text { Pathological type } \\
\text { por, sig/ tub1, tub2 }\end{array}$ & $9 / 144$ & 6.240 & $1.793-16.84$ & $0.006^{\mathrm{a}}$ & 2.099 & $0.585-5.991$ & 0.230 \\
\hline $\begin{array}{l}\text { Lymph invasion } \\
\text { Positive/Negative }\end{array}$ & $96 / 57$ & 19.18 & $4.095-342.0$ & $<0.001^{\mathrm{a}}$ & 7.628 & $1.441-141.2$ & $0.012^{\mathrm{a}}$ \\
\hline $\begin{array}{l}\text { Venous invasion } \\
\text { Positive/Negative }\end{array}$ & $74 / 49$ & 6.571 & $2.713-19.55$ & $<0.001^{\mathrm{a}}$ & 2.345 & $0.896-7.406$ & 0.084 \\
\hline $\begin{array}{l}\text { Tumor invasion } \\
\text { T3-4/T0-2 }\end{array}$ & $117 / 36$ & 4.820 & $1.443-29.89$ & $0.007^{\mathrm{a}}$ & 2.000 & $0.555-12.87$ & 0.322 \\
\hline $\begin{array}{l}\text { Lymph node metasta } \\
\text { Positive/Negative }\end{array}$ & $73 / 80$ & 5.236 & $2.264-14.20$ & $<0.001^{\mathrm{a}}$ & 2.465 & $0.998-7.059$ & 0.050 \\
\hline $\begin{array}{l}\text { GOPC expression } \\
\text { Low/High }\end{array}$ & 76/77 & 2.558 & $1.198-5.912$ & $0.014^{\mathrm{a}}$ & 1.902 & $0.853-4.552$ & 0.117 \\
\hline
\end{tabular}

${ }^{\text {a }}<<0.05$. HR, hazard ratio; 95\% CI, 95\% confidence interval; T, tumor; GOPC, Golgi-associated PDZ- and coiled-coil motif-containing.

Table IV. Correlation between GOPC expression and adjuvant chemotherapy or recurrence.

\begin{tabular}{lccc}
\hline & \multicolumn{2}{c}{ GOPC expression } & \\
\cline { 2 - 3 } Variables & $\begin{array}{c}\text { High group } \\
(\mathrm{n}=67)\end{array}$ & $\begin{array}{c}\text { Low group } \\
(\mathrm{n}=64)\end{array}$ & P-value \\
\hline Adjuvant & & & \\
chemotherapy & & & \\
$\quad$ Yes & 27 & 24 & 0.857 \\
No & 40 & 40 & \\
Recurrence & & & \\
Yes & 8 & 17 & $0.049^{\mathrm{a}}$ \\
No & 59 & 47 & \\
Site & 2 & 3 & \\
Local & 1 & 4 & \\
Lymph node & 3 & 3 & \\
Liver & 1 & 5 & \\
Lung & 1 & 2 & \\
Pleura & 0 & 0 & \\
Other & & & \\
\hline
\end{tabular}

${ }^{\mathrm{a}} \mathrm{P}<0.05$. GOPC, Golgi-associated $\mathrm{PDZ}-$ and coiled-coil motif-containing.

syntaxin-6 involved in endocytosis (19), cluster of differentiation-46 in autophagy (20) and claudin- 1 and claudin-2 in tight junctions (21). In glioblastoma, GOPC (or FIG) is reported to fuse with the c-ros-oncogene 1 (ROS), a type of receptor tyrosine kinase, yielding the so-called FIG-ROS (22). Certain studies have indicated that FIG-ROS performs oncogenic roles in several processes, including cellular proliferation, colony formation, cell cycle progression, migration and invasion in intrahepatic cholangiocarcinoma $(23,24)$. To the best of our knowledge, no study has previously been published regarding GOPC and FIG-ROS in colorectal cancer.

GOPC mRNA expression was evaluated in 153 colorectal cancer specimens by RT-qPCR and the correlation between GOPC expression and prognosis was analyzed. In the analyses of the clinicopathological factors, the proportion of venous invasion was significantly increased in the GOPC low group compared with in the GOPC high group, as was the proportion of cancer recurrence. The number of stage IV cases (11 in GOPC low, 7 in GOPC high) and the number of hematogenous metastasis cases ( 8 in GOPC low, 4 in GOPC high) were greater in the GOPC low group. Multivariate analysis for RFS identified lower expression of GOPC to be an independent prognostic factor.

To compare the expression of GOPC mRNA and protein between normal colorectal mucosa and cancerous tissue, RT-qPCR and immunohistochemical analysis were performed. The expression of GOPC mRNA and protein in the normal colorectal mucosa was increased compared with cancer tissue, suggesting that the colorectal mucosa loses GOPC expression during carcinogenesis events. Immunohistochemical analysis demonstrated that the expression of GOPC protein in cancer tissue, particularly in front invasion of cancer, was lower compared with normal mucosa. Combined with the RT-qPCR and immunohistochemical findings of GOPC expression, this result suggests that loss of GOPC performs an important role in cancer malignancy.

GOPC also controls postendocytic sorting of several receptors toward lysosomal degradation (25-28) and reduces 
Table V. Results of univariate and multivariate analyses for recurrence-free survival in a Cox proportional hazards model.

\begin{tabular}{|c|c|c|c|c|c|c|c|}
\hline \multirow[b]{2}{*}{ Characteristics } & \multirow[b]{2}{*}{$\mathrm{n}$} & \multicolumn{3}{|c|}{ Univariate analysis } & \multicolumn{3}{|c|}{ Multivariate analysis } \\
\hline & & HR & $95 \% \mathrm{CI}$ & P-value & HR & $95 \% \mathrm{CI}$ & P-value \\
\hline \multicolumn{8}{|l|}{ Gender } \\
\hline Male/Female & $85 / 46$ & 1.072 & $0.471-2.646$ & 0.870 & & & \\
\hline \multicolumn{8}{|l|}{ Pathological type } \\
\hline Por, sig/tub1, tub2 & $5 / 126$ & 5.208 & $1.228-15.15$ & $0.028^{\mathrm{a}}$ & 2.618 & $0.578-8.711$ & 0.187 \\
\hline \multicolumn{8}{|l|}{ Lymph invasion } \\
\hline Positive/Negative & $77 / 54$ & 3.841 & $1.453-13.20$ & $0.005^{\mathrm{a}}$ & 2.966 & $0.9903-10.96$ & 0.052 \\
\hline \multicolumn{8}{|l|}{ Venous invasion } \\
\hline Positive/Negative & $57 / 74$ & 1.654 & $0.739-3.767$ & 0.218 & 1.672 & $0.639-4.365$ & 0.290 \\
\hline \multicolumn{8}{|l|}{ Tumor invasion } \\
\hline T3-4/T0-2 & $95 / 36$ & 2.837 & $0.978-12.04$ & 0.055 & & & \\
\hline \multicolumn{8}{|c|}{ Lymph node metastasis } \\
\hline Positive/Negative & $55 / 76$ & 3.555 & $1.533-9.195$ & $0.002^{\mathrm{a}}$ & 2.861 & $1.138-7.880$ & $0.024^{\mathrm{a}}$ \\
\hline \multicolumn{8}{|l|}{ GOPC expression } \\
\hline Low/High & $64 / 67$ & 2.706 & $1.167-7.000$ & $0.019^{\mathrm{a}}$ & 2.800 & $1.121-7.648$ & $0.027^{\mathrm{a}}$ \\
\hline
\end{tabular}

${ }^{a} \mathrm{P}<0.05$. HR, hazard ratio; 95\% $\mathrm{CI}, 95 \%$ confidence interval.

A

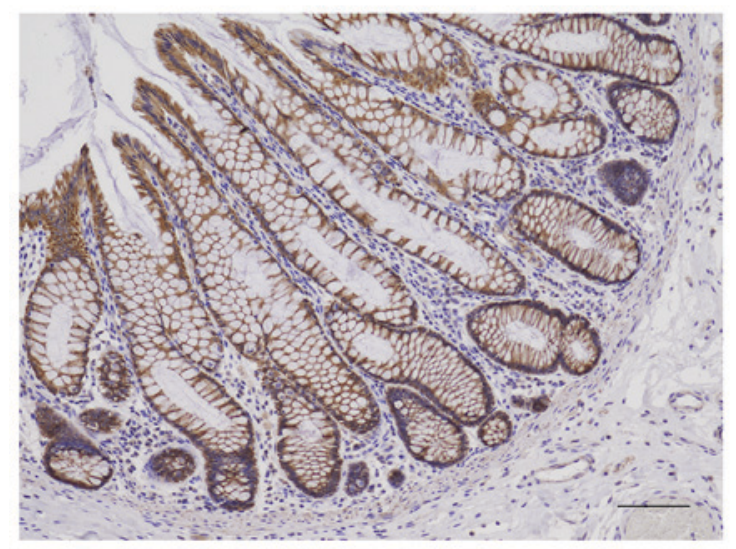

C

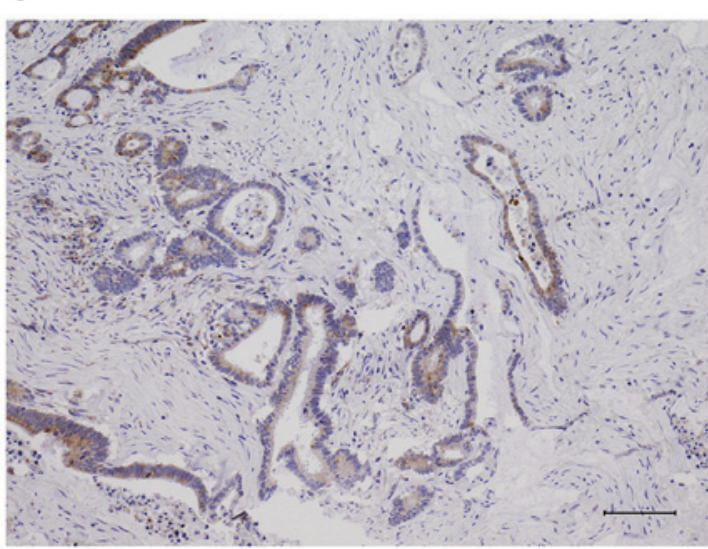

B

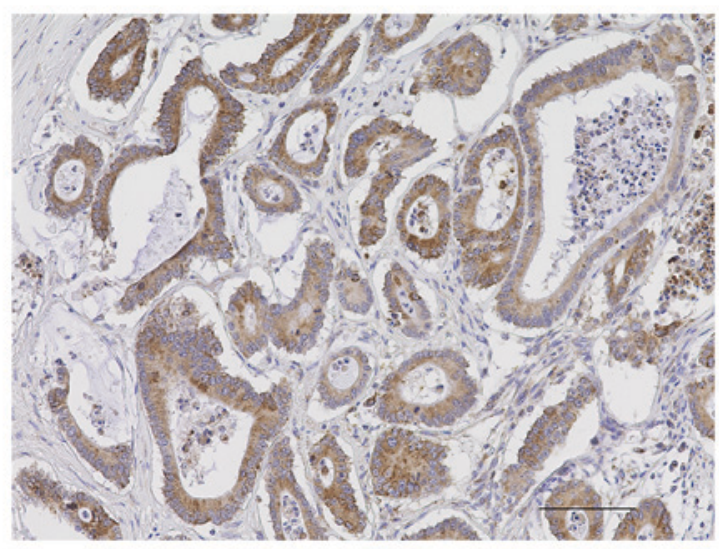

D

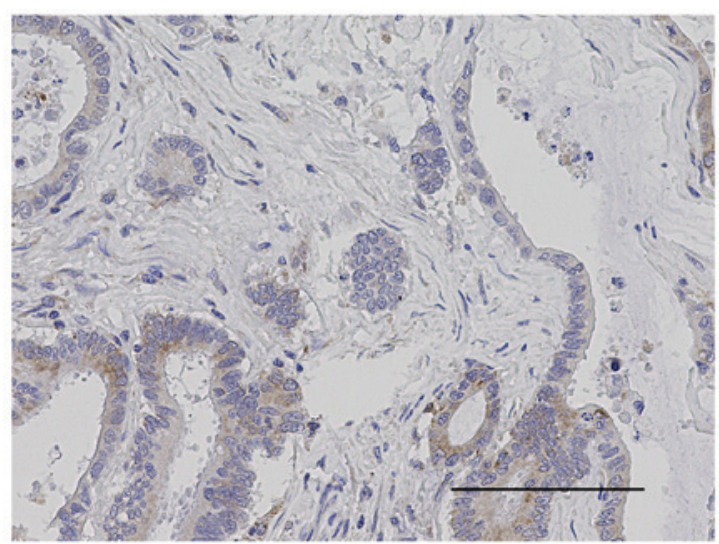

Figure 4. GOPC protein expression. (A) In normal colorectal mucosa, the GOPC protein was strongly expressed and localized in cytoplasm or cell membrane. Magnification, x10. (B) GOPC protein expression in colorectal cancer tissue. Magnification, x15. (C) GOPC protein expression in colorectal cancer tissue. Magnification, x10. (D) GOPC protein expression in colorectal cancer tissue at the invasion front of cancer at interstitial tissue. Magnification, $\mathrm{x} 30$. In colorectal cancer, expression of GOPC was observed to be relatively low at (C and D) deeper levels compared with (B) the surface area. Scale bar, $100 \mu \mathrm{m}$. GOPC, Golgi-associated PDZ- and coiled-coil motif-containing. 
the amount of cell surface receptors $(29,30)$. GOPC binds to $G$ protein-coupled receptors with a PDZ ligand motif, including metabotropic glutamate receptors $(31,32)$, the somatostatin receptor subtype $5(30,33)$. It was recently reported that GOPC knockdown in the HEK293 cell line reduces internalized $\beta 1-\mathrm{AR}$ and increases cell surface $\beta 1-\mathrm{AR}$ (34). Thus, activation of the MAPK-Erk1/2 pathway was induced increasingly by $\beta 1$-AR agonists. The MAPK-Erk1/2 pathway is a cellular signal transduction pathway that can regulate cell differentiation, proliferation and cell cycle progression and is a major pathway inducing the progression of colorectal cancer (9-13). The present study revealed that lower expression of GOPC increases the risk of recurrence, metastasis, and a poor prognosis in colorectal cancer. In colorectal cancer, whether GOPC expression increases activation of MAPK-Erk1/2 via the $\beta 1$-AR cascade remains unknown. In addition, although the present study suggested that the lower expression of GOPC increases the proportion of recurrence subsequent to chemotherapy, there is no report that has clarified the correlation of GOPC expression and chemoresistance. The authors are now preparing in vitro and in vivo assays focusing on the GOPC- $31-A R-M A P K-E r k 1 / 2$ pathway in colorectal cancer.

The present study demonstrated that lower GOPC expression significantly correlates with poorer OS and RFS. To the best of our knowledge, the present study is the first to clarify the correlation between GOPC expression and prognosis in colorectal cancer and demonstrates that GOPC is a possible marker for poor prognosis in this disease.

\section{Acknowledgements}

The authors would like to express special thanks to all surgeons working at Minoh City Hospital, Kansai Rosai Hospital, Kinki Central Hospital of the Mutual Aid Association of Public School Teachers, National Hospital Organization Osaka National Hospital, NTT (Nippon Telegraph And Telephone) West Osaka Hospital, Osaka Medical Center for Cancer and Cardiovascular Diseases, Saiseikai Suita Hospital, Sakai City Medical Center, Toyonaka Municipal Hospital (all in Osaka, Japan). The authors would also like to thank Ms. Yurika Nakamura for technical assistance.

\section{References}

1. Siegel RL, Miller KD and Jemal A: Cancer statistics, 2015. CA Cancer J Clin 65: 5-29, 2015.

2. Jonker DJ, O'Callaghan CJ, Karapetis CS, Zalcberg JR, Tu D, Au HJ, Berry SR, Krahn M, Price T, Simes RJ, et al: Cetuximab for the treatment of colorectal cancer. N Engl J Med 357: 2040-2048, 2007.

3. Karapetis CS, Khambata-Ford S, Jonker DJ, O'Callaghan CJ, Tu D, Tebbutt NC, Simes RJ, Chalchal H, Shapiro JD, Robitaille S, et al: K-ras mutations and benefit from cetuximab in advanced colorectal cancer. N Engl J Med 359: 1757-1765, 2008.

4. Hurwitz H, Fehrenbacher L, Novotny W, Cartwright T, Hainsworth J, Heim W, Berlin J, Baron A, Griffing S, Holmgren E, et al: Bevacizumab plus irinotecan, fluorouracil, and leucovorin for metastatic colorectal cancer. N Engl J Med 350: 2335-2342, 2004.

5. Van Cutsem E, Peeters M, Siena S, Humblet Y, Hendlisz A, Neyns B, Canon JL, Van Laethem JL, Maurel J, Richardson G, et al: Open-label phase III trial of panitumumab plus best supportive care compared with best supportive care alone in patients with chemotherapy-refractory metastatic colorectal cancer. J Clin Oncol 25: 1658-1664, 2007.
6. Grothey A, Van Cutsem E, Sobrero A, Siena S, Falcone A, Ychou M, Humblet Y, Bouché O, Mineur L, Barone C, et al: Regorafenib monotherapy for previously treated metastatic colorectal cancer (CORRECT): An international, multicentre, randomised, placebo-controlled, phase 3 trial. Lancet 381: 303-312, 2013.

7. Adachi T, Hinoi T, Egi H, Shimomura M and Ohdan H: Oxaliplatin and molecular-targeted drug therapies improved the overall survival in colorectal cancer patients with synchronous peritoneal carcinomatosis undergoing incomplete cytoreductive surgery. Surg Today 45: 986-992, 2015.

8. Beppu N, Yoshie H, Kimura F, Aihara T, Doi H, Kamikonya N, Matsubara N, Tomita N, Yanagi H and Yamanaka N: The short-term outcomes of induction SOX (S-1 + oxaliplatin) +/- cetuximab chemotherapy followed by short-course chemoradiotherapy in patients with poor-risk locally advanced rectal cancer. Surg Today 46: 1123-1131, 2016.

9. Dhillon AS, Hagan S, Rath O and Kolch W: MAP kinase signalling pathways in cancer. Oncogene 26: 3279-3290, 2007.

10. Keyse SM: Dual-specificity MAP kinase phosphatases (MKPs) and cancer. Cancer Metastasis Rev 27: 253-261, 2008.

11. Johnson GL and Lapadat R: Mitogen-activated protein kinase pathways mediated by ERK, JNK, and p38 protein kinases. Science 298: 1911-1912, 2002.

12. Dunn KL, Espino PS, Drobic B, He S and Davie JR: The Ras-MAPK signal transduction pathway, cancer and chromatin remodeling. Biochem Cell Biol 83: 1-14, 2005.

13. Yoon S and Seger R: The extracellular signal-regulated kinase: Multiple substrates regulate diverse cellular functions. Growth Factors 24: 21-44, 2006

14. Leslie H. Sobin MKG and Christian Wittekind: TNM classification of malignant tumors. 7th ed. Wiley-Blackwell, 2011.

15. Larionov A, Krause A and Miller W: A standard curve based method for relative real time PCR data processing. BMC Bioinformatics 6: 62, 2005.

16. Yao R, Maeda T, Takada S and Noda T: Identification of a PDZ domain containing Golgi protein, GOPC, as an interaction partner of frizzled. Biochem Biophys Res Commun 286: 771-778, 2001.

17. Neudauer CL, Joberty G and Macara IG: PIST: A novel PDZ/coiled-coil domain binding partner for the rho-family GTPase TC10. Biochem Biophys Res Commun 280: 541-547, 2001.

18. Pelaseyed T and Hansson GC: CFTR anion channel modulates expression of human transmembrane mucin MUC3 through the PDZ protein GOPC. J Cell Sci 124: 3074-3083, 2011.

19. Charest A, Lane K, McMahon K and Housman DE: Association of a novel PDZ domain-containing peripheral Golgi protein with the Q-SNARE (Q-soluble N-ethylmaleimide-sensitive fusion protein (NSF) attachment protein receptor) protein syntaxin 6 . J Biol Chem 276: 29456-29465, 2001.

20. Meiffren G, Joubert PE, Gregoire IP, Codogno P, Rabourdin-Combe $\mathrm{C}$ and Faure M: Pathogen recognition by the cell surface receptor CD46 induces autophagy. Autophagy 6: 299-300, 2010.

21. Lu R, Stewart L and Wilson JM: Scaffolding protein GOPC regulates tight junction structure. Cell Tissue Res 360: 321-332, 2015.

22. Charest A, Lane K, McMahon K, Park J, Preisinger E, Conroy H and Housman D: Fusion of FIG to the receptor tyrosine kinase ROS in a glioblastoma with an interstitial del(6)(q21q21). Genes Chromosomes Cancer 37: 58-71, 2003.

23. Saborowski A, Saborowski M, Davare MA, Druker BJ, Klimstra DS and Lowe SW: Mouse model of intrahepatic cholangiocarcinoma validates FIG-ROS as a potent fusion oncogene and therapeutic target. Proc Natl Acad Sci USA 110: 19513-19518, 2013.

24. Deng G, Hu C, Zhu L, Huang F, Huang W, Xu H and Nie W: Downregulation of ROS-FIG inhibits cell proliferation, colony formation, cell cycle progression, migration and invasion, while inducing apoptosis in intrahepatic cholangiocarcinoma cells. Int J Mol Med 34: 661-668, 2014.

25. Cheng J, Cebotaru V, Cebotaru L and Guggino WB: Syntaxin 6 and CAL mediate the degradation of the cystic fibrosis transmembrane conductance regulator. Mol Biol Cell 21: 1178-1187, 2010.

26. Cheng J, Moyer BD, Milewski M, Loffing J, Ikeda M, Mickle JE, Cutting GR, Li M, Stanton BA and Guggino WB: A Golgi-associated PDZ domain protein modulates cystic fibrosis transmembrane regulator plasma membrane expression. J Biol Chem 277: 3520-3529, 2002. 
27. Cheng J, Wang H and Guggino WB: Regulation of cystic fibrosis transmembrane regulator trafficking and protein expression by a Rho family small GTPase TC10. J Biol Chem 280: 3731-3739, 2005.

28. Cao TT, Deacon HW, Reczek D, Bretscher A and von Zastrow M: A kinase-regulated PDZ-domain interaction controls endocytic sorting of the beta2-adrenergic receptor. Nature 401: 286-290, 1999.

29. He J, Bellini M, Xu J, Castleberry AM and Hall RA: Interaction with cystic fibrosis transmembrane conductance regulator-associated ligand (CAL) inhibits beta1-adrenergic receptor surface expression. J Biol Chem 279: 50190-50196, 2004.

30. Bauch C, Koliwer J, Buck F, Hönck HH and Kreienkamp HJ: Subcellular sorting of the G-protein coupled mouse somatostatin receptor 5 by a network of PDZ-domain containing proteins. PLoS One 9: e88529, 2014.
31. Cheng S, Zhang J, Zhu P, Ma Y, Xiong Y, Sun L, Xu J, Zhang H and He J: The PDZ domain protein CAL interacts with mGluR5a and modulates receptor expression. J Neurochem 112: 588-598, 2010.

32. Zhang J, Cheng S, Xiong Y, Ma Y, Luo D, Jeromin A, Zhang $\mathrm{H}$ and $\mathrm{He} \mathrm{J}$ : A novel association of mGluRla with the PDZ scaffold protein CAL modulates receptor activity. FEBS Lett 582: 4117-4124, 2008

33. Wente W, Stroh T, Beaudet A, Richter D and Kreienkamp HJ: Interactions with PDZ domain proteins PIST/GOPC and PDZK1 regulate intracellular sorting of the somatostatin receptor subtype 5. J Biol Chem 280: 32419-32425, 2005.

34. Koliwer J, Park M, Bauch C, von Zastrow M and Kreienkamp HJ: The golgi-associated PDZ domain protein PIST/GOPC stabilizes the $\beta 1$-adrenergic receptor in intracellular compartments after internalization. J Biol Chem 290: 6120-6129, 2015. 